\title{
THE
}

\section{Pyrethroid insecticides: Isoform-dependent hydrolysis, induction of cytochrome P450 3A4 and evidence on the involvement of the pregnane $X$ receptor}

\author{
Dongfeng Yang \\ University of Rhode Island \\ Xiliang Wang \\ University of Rhode Island \\ Yi-tzai Chen \\ University of Rhode Island \\ Ruitang Deng \\ University of Rhode Island, dengr@uri.edu \\ Follow this and additional works at: https://digitalcommons.uri.edu/bps_facpubs \\ Bingfang Yan

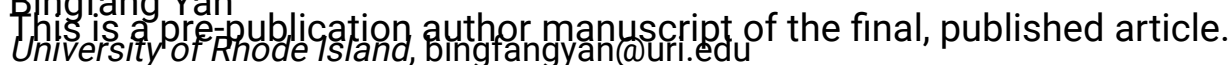 \\ Creative Commons License \\ c) (i) $\Theta \Theta$
}

This work is licensed under a Creative Commons Attribution-Noncommercial-No Derivative Works 4.0 License.

\section{Citation/Publisher Attribution}

Yang, D., Wang, X., Chen, Y-T., Deng, R., \& Yan, B. (2009). Pyrethroid insecticides: Isoform-dependent hydrolysis, induction of cytochrome P450 3A4 and evidence on the involvement of the pregnane $\mathrm{X}$ receptor. Toxicology and Applied Pharmacology, 237(1), 49-58. doi: 10.1016/j.taap.2009.02.012 Available at: https://doi.org/10.1016/j.taap.2009.02.012

This Article is brought to you for free and open access by the Biomedical and Pharmaceutical Sciences at DigitalCommons@URI. It has been accepted for inclusion in Biomedical and Pharmaceutical Sciences Faculty Publications by an authorized administrator of DigitalCommons@URI. For more information, please contact digitalcommons-group@uri.edu. 


\title{
PYRETHROID INSECTICIDES: ISOFORM-DEPENDENT HYDROLYSIS, INDUCTION OF CYTOCHROME P450 3A4 AND EVIDENCE ON THE INVOLVEMENT OF THE PREGNANE X RECEPTOR
}

\author{
Dongfang Yang, Xiliang Wang, Yi-tzai Chen, Ruitang Deng, and Bingfang Yan \\ Department of Biomedical and Pharmaceutical Sciences, Center for Pharmacogenomics and \\ Molecular Therapy, University of Rhode Island Kingston, RI 02881
}

\begin{abstract}
Pyrethroids account for more than one-third of the insecticides currently marketed in the world. In mammals, these insecticides undergo extensive metabolism by carboxylesterases and cytochrome P450s (CYPs). In addition, some pyrethroids are found to induce the expression of CYPs. The aim of this study was to determine whether pyrethroids induce carboxylesterases and CYP3A4, and whether the induction is correlated inversely with their hydrolysis. Human liver microsomes were pooled and tested for the hydrolysis of 11 pyrethroids. All pyrethroids were hydrolyzed by the pooled microsomes, but the hydrolytic rates varied by as many as 14 fold. Some pyrethroids such as bioresmethrin were preferably hydrolyzed by carboxylesterase HCE1, whereas others such as bifenthrin preferably by HCE2. In primary human hepatocytes, all pyrethroids except tetramethrin significantly induced CYP3A4. In contrast, insignificant changes were detected on the expression of carboxylesterases. The induction of CYP3A4 was confirmed in multiple cell lines including HepG2, Hop92 and LS180. Overall, the magnitude of the induction was correlated inversely with the rates of hydrolysis, but positively with the activation of the pregnane $\mathrm{X}$ receptor (PXR). Transfection of a carboxylesterase markedly decreased the activation of PXR, and the decrease was in agreement with carboxylesterase-based preference for hydrolysis. In addition, human PXR variants as well as rat PXR differed from human PXR (wild-type) in responding to certain pyrethroids (e.g., lambda-cyhalothrin), suggesting that induction of PXR target genes by these pyrethroids varies depending on polymorphic variants and the PXR species identity.
\end{abstract}

\section{INTRODUCTION}

Pyrethroids constitute a major class of insecticides and account for more than one-third of the insecticides currently marketed in the world (Dich et al., 1997; Casida and Quistad, 1998; Adelsbach and Tjeerdema, 2003). In addition to crop and forestry protection, pyrethroid insecticides are widely used for health programs such as parasite eradication and disinfection of public facility (Heudorf and Angerer, 2001). There are two types of pyrethroids: type II

(C) 2009 Elsevier Inc. All rights reserved.

Address Correspondence to: Dr. Bingfang Yan, Department of Biomedical and Pharmaceutical Sciences, University of Rhode Island, Kingston, RI 02881, Phone: (401) 874-5032, Fax: (401) 874-5048, byan@uri.edu.

Publisher's Disclaimer: This is a PDF file of an unedited manuscript that has been accepted for publication. As a service to our customers we are providing this early version of the manuscript. The manuscript will undergo copyediting, typesetting, and review of the resulting proof before it is published in its final citable form. Please note that during the production process errors may be discovered which could affect the content, and all legal disclaimers that apply to the journal pertain.

Conflict of Interest Statement: None 
compounds contain a cyano moiety in the $\alpha$-position, whereas those without the cyano group belong to type I pyrethroids. Introduction of the cyano moiety drastically increases the insecticidal activity as well as lethal potency in rodents (Elliott, 1976; Soderlund and Knipple, 2003). In addition, type I and II pyrethroids cause distinct sets of symptoms after acute poisoning. Type I pyrethroids induce sparring, whole-body tremor and prostration, whereas type II pyrethroids induce burrowing, salivation, writhing and dermal tingling (Wolansky and Harrill, 2008). In addition to acute poisoning, emerging experimental data suggest that many pyrethroids during chronic exposure act as endocrine disruptors and even involve carcinogenesis (Dich et al., 1997; Perry et al., 2007).

Pyrethroids, compared with other types of insecticides such as organophosphates, show higher selectivity toward their intended species (i.e., insects) over non-intended species such as mammals. In both insect and mammalian species, pyrethroids act on voltage-sensitive sodium channels and exert neurotoxicity. However, the mammalian channels are much less sensitive than their insect counterparts (Vais et al., 2001). In addition, mammalian species have a greater metabolic capacity, leading to rapid elimination of exposed pyrethroids. Studies in rodents and epidemiological data have shown that pyrethroids undergo extensive metabolism by carboxylesterases and cytochrome P450s (CYPs) (Anand et al., 2006; Godin et al., 2006; Nishi et al., 2006; Ross et al., 2006; Crow et al., 2007; Godin et al., 2007). Hydrolysis of pyrethroids is generally considered a detoxication process (Casida et al., 1983; Cantalamessa, 1993). In rats, pretreatment with tri-o-tolyl phosphate (a carboxylesterase inhibitor) significantly increases the mortality of pyrethroids (Cantalamessa, 1993). The oxidative metabolism by CYPs, on the other hand, may have opposite toxicological consequences depending on a pyrethriod or even a test system. CYP inducers phenobarbital and 3-methylcholanthrene potentiate deltamethrin (a pyrethriod) in the induction of neurobehavioral toxicity (Dayal et al., 2003), whereas hepatoxicity of pyrethroid cypermethrin is markedly decreased in primary hepatocytes pretreated by phenobarbital (EL-Tawil and Abdel-Rahman, 2001).

In addition to acting as CYP substrates, some pyrethroids are found to induce CYP enzymes. In rat primary hepatocytes, cypermethrin significantly increases the activity of ethoxyresorufin- $O$-deethylase, an indicator for CYP1A induction (Delescluse et Al., 1998). In the same culturing system, permethrin induces CYP2B1 and CYP3A23 (Heder et al., 2001). The induction even lasts from dam to offspring. In rats, prenatal exposure to deltamethrin induces several major CYP enzymes and the induction persists postnatally up to 6-9 weeks depending on the initial doses (Johri 2006). In addition to rat CYPs, a pyrethrum extract has recently been shown to induce CYP enzymes in human hepatocytes (Price et al., 2008). Cypermethrin and fenvelarate are potent activators of the pregnane X receptor (PXR), a master regulator that supports induction of various types of drug-metabolizing enzymes including CYP enzymes (Lemaire et al., 2004).

The aim of this study was to determine whether pyrethroids induce carboxylesterases and CYP3A4, and whether the induction is correlated inversely with the hydrolysis of these compounds. A panel of 11 pyrethroids (Table I, Fig. 1) was initially tested for hydrolysis by pooled human liver microsomes. All pyrethroids were hydrolyzed, but the rates varied by as many as 14 fold. Some pyrethroids were hydrolyzed preferably by carboxylesterase HCE1, whereas others by HCE2. In primary human hepatocytes, all pyrethroids except tetramethrin significantly induced CYP3A4 but caused little changes in the expression of carboxylesterases. Overall, the magnitude of the induction was inversely correlated with the rates of hydrolysis, but positively correlated with the activation of PXR. Transfection of a carboxylesterase markedly decreased PXR activation, and the decrease was in agreement with carboxylesterasebased preference for hydrolysis. 


\section{MATERIALS AND METHODS}

\section{Chemicals and supplies}

All pyrethroids were purchased from ChemService (West Chester, PA), and the purity and composition of isomers are listed in Table I. Hanks balanced salt solution, pregnenolone 16 $\alpha$ carbonitrle (PCN) and William's medium E (WME) were purchased from Sigma (St. Louis, MO). Eagle's minimum Essential medium (EMEM) and Insulin-Transferrin-Selenium (ITS) G supplement were purchased from Invitrogen (Carlsbad, CA). Dual-Luciferase Reporter Assay System was from Promega (Madison, WI). Fetal bovine serum (FBS) was from HyClone laboratories (Logan, UT). Taqman probes (Table II) were from Applied Biosystem Incorporate (Foster City, CA). Microsomes from baculovirus-infected insect cells (Supersomes) coexpressing CYP3A4/P450 reductase/b5 and control Supersomes were purchased from BD Biosciences (Woburn, MA). Unless otherwise specified, all other reagents were purchased from Fisher Scientific (Fair Lawn, NJ).

\section{Hydrolysis of pyrethroids}

Hydrolysis of pyrethroids was determined with human liver microsomes (Tang et al., 2006) and cell lysates containing recombinant HCE1 and HCE2. Lysates were prepared from stable transfected insect cell lines (Zhu et al., 2000). The abundance of HCE1 or HCE2 in the lysates was estimated according to immunostaining intensities generated with serial amounts of purified HCE1 and HCE2. Enzymatic reactions were carried out at $37^{\circ} \mathrm{C}$ in a total volume of $150 \mu 1$. Samples (usually $50 \mu \mathrm{g}$ protein) were prepared in $75 \mu \mathrm{l}$ Tris- $\mathrm{HCl}$ buffer $(50 \mathrm{mM}, \mathrm{pH}$ $7.4)$ and then mixed with an equal volume of a pyrethroid $(200 \mu \mathrm{M})$ in the same buffer. The incubations lasted for 20-60 min depending on a pyrethroid, which kept the metabolism in the linear range. The reactions were terminated with $300 \mu \mathrm{l}$ of acetonitrile containing naproxen (2 $\mu \mathrm{g} / \mathrm{ml}$ ) or clopidogrel $(16 \mu \mathrm{g} / \mathrm{ml})$ as the IS (internal standard). The reaction mixtures were subjected to centrifugation for $15 \mathrm{~min}$ at $4^{\circ} \mathrm{C}(15,000 \mathrm{~g})$ to remove proteins.

\section{Metabolism of pyrethroids by recombinant CYP3A4}

Oxidation of pyrethroids by CYP3A4 was determined, essentially as described previously (Yang and Yan, 2007). Preliminary studies were conducted to determine conditions supporting a linear metabolic rate including the incubation time, the amount of CYP3A4 and the concentrations of a pyrethroid. The incubation reactions were performed in a total volume of $100 \mu 1$. The reaction mixtures contained Supersomes (5 pmol P450) co-expressing P450 reductase and b5, potassium phosphate buffer (50 mM, pH 7.4), $\mathrm{MgCl}_{2}(3 \mathrm{mM})$, EDTA (1 $\mathrm{mM})$, and a pyrethroid $(50 \mu \mathrm{M})$. Reactions were initiated by the addition of the NADPHregenerating system (NRS), consisting of NADP $(1 \mathrm{mM})$, glucose 6-phosphate $(1 \mathrm{U} / \mathrm{ml})$, and glucose-6-phosphate dehydrogenase $(5 \mathrm{mM})$, placed in a shaking incubator at $37^{\circ} \mathrm{C}$, and terminated by the addition of $200 \mu \mathrm{l}$ of acetonitrile after 10 to $60 \mathrm{~min}$ depending on a pyrethroid. Esfenvalerate $(4 \mu \mathrm{g} / \mathrm{ml})$ served as the internal standard for bifenthrin metabolism, whereas bifenthrin $(4 \mu \mathrm{g} / \mathrm{ml})$ served as the IS for the metabolism of all other pyrethroids. Several controls were performed including: zero-time incubation, exclusion of the NRS, and Supersomes expressing no P450. The metabolism was detected only with CYP3A4 Supersomes in the presence of the NRS.

\section{High-performance liquid chromatography (HPLC)}

Hydrolysis of pyrethroids was monitored by HPLC (Hitachi LaChrom Elite-300) with a Chromolith SpeedROD column RP-18e (Merck, Germany). The supernatants (10-30 $\mu$ l) of the reaction mixtures were injected and separated by a gradient mobile phase consisting of acetonitrile and formic acid $(0.01 \%)$. The gradient was run at 20-50\% acetonitrile (v/v) for 6 $\mathrm{min}, 50-80 \%$ for $5 \mathrm{~min}$ followed by $80-20 \%$ for $6 \mathrm{~min}$. The flow rate was $2 \mathrm{ml} / \mathrm{min}$ and 
disappearance of a parent compound was monitored by a diode array detector at $230 \mathrm{~nm}$. Two injections were made for each sample and all reactions were conducted three times with the same batch of enzyme preparations. All quantifications were performed using peak area ratios and calibration curves generated from the corresponding internal control.

\section{Culture and treatment of human primary hepatocytes and cell lines}

Plated human primary hepatocytes (in 12-well plate) were obtained from the Liver Tissues Procurement and Distribution System (University of Minnesota) or commercial sources (CellzDirect, Pittsboro, NC). Four donors were included with two males (35 and 62 years old) and two females (39 and 54 years old). Among the donors, three were Caucasian and one Africa American (the 35-year male). None of them was smoker. Upon arrival, medium was replaced with rich WME containing ITS supplement and penicillin $(100 \mathrm{U} / \mathrm{ml}) /$ streptomycin $(10 \mu \mathrm{g} / \mathrm{ml})$ (Ma et al., 2004). After incubation at $37^{\circ} \mathrm{C}$ with $5 \% \mathrm{CO}_{2}$ for $24 \mathrm{~h}$, hepatocytes were treated with a pyrethroid $(10 \mu \mathrm{M})$ for $24 \mathrm{~h}$. Three cell lines were used including hepatoma line HepG2, lung large cell carcinoma line Hop92 and colorectal adenocarcinoma line LS180. HepG2 and LS180 were purchased from the American Type Culture Collection (Rockville, MD), whereas Hop92 was from the National Cancer Institute. The cell lines were cultured in EMEM supplemented with $10 \%$ FBS, penicillin/streptomycin, 1x non-essential amino acids. Cell lines were usually seeded at a density of $2.5 \times 10^{5}$ cells/well (12-well plates), and treatment (delipided serum) was performed $12 \mathrm{~h}$ after seeding. Similarly to primary hepatocytes, the treatment lasted for $24 \mathrm{~h}$.

\section{Reverse transcription-quantitative polymerase chain reaction (RT-qPCR)}

Total RNA was isolated with an RNA-Bee (Friendswood, TX) according to the manufacturer's manual, and the integrity of the RNA was confirmed by electrophoresis. RNA ( $1 \mu \mathrm{g})$ was subjected to the synthesis of the first strand cDNA in a total volume of $25 \mu 1$ with random primers and M-MLV reverse transcriptase. The reactions were conducted at $25^{\circ} \mathrm{C}$ for $10 \mathrm{~min}$, $42^{\circ} \mathrm{C}$ for $50 \mathrm{~min}$ and $70^{\circ} \mathrm{C}$ for $10 \mathrm{~min}$. The cDNAs were then diluted 8 times and RT-qPCR was conducted with TaqMan Gene Expression Assay (Applied Biosystems, Foster City, CA) (Yang et al., 2007). The PCR amplification was conducted in a total volume of $20 \mu \mathrm{l}$ containing universal PCR master mixture $(10 \mu \mathrm{l})$, gene-specific TaqMan assay mixture $(1 \mu \mathrm{l})$, and cDNA template $(6 \mu \mathrm{l})$. Cycling profile was $50^{\circ} \mathrm{C}$ for $2 \mathrm{~min}, 95^{\circ} \mathrm{C}$ for $10 \mathrm{~min}$, followed by 40 cycles of $15 \mathrm{~s}$ at $95^{\circ} \mathrm{C}$ and $1 \mathrm{~min}$ at $60^{\circ} \mathrm{C}$, as recommended by the manufacturer. The mRNA levels were normalized according to the level of GAPDH and RNA polymerase II (selected samples). Amplification and quantification were done with the Applied Biosystems 7900 Real-Time PCR System.

\section{Cotransfection and activation of human PXR}

The activation of human PXR was performed in a stable line (hPXR-HRE) constitutively expressing human PXR and harboring a PXR element luciferase reporter (Song et al., 2004). This line was maintained in EMEM medium supplemented with $10 \%$ FBS and antibiotics (Zeocin, $300 \mu \mathrm{g} / \mathrm{ml}$; blasticidin, $5 \mu \mathrm{g} / \mathrm{ml}$ ). To determine the activation of PXR by pyrethroids, the hPXR-HRE cells were plated in 96-well plates at $4 \times 10^{4} /$ well. After an overnight incubation, the cells were treated for $24 \mathrm{~h}$ with a pyrethroid at $10 \mu \mathrm{M}$ in $10 \%$ delipided FBS without antibiotics. Cell lysates were then prepared and analyzed for luciferase activity. The signal was normalized with the amount of protein. To determine the effect of hydrolysis on the activation of PXR, hPXR-HRE cells were plated in 6-well-paltes and transfected with HCE1, HCE2 or the corresponding vector (Xie et al., 2002). After a 24-h culturing, the transfected cells were harvested, combined and plated again in 48 -well plates at $8 \times 10^{4} /$ well. After another 12-h culturing, the cells were treated with a pyrethroid for $24 \mathrm{~h}$ and luciferase activity was 
subsequently determined. It should be noted that no evident changes were observed on the cell viability with the treatment.

The activation of rat PXR and polymorphic mutants of human PXR was conducted with cotransfection as described previously (Song et al., 2005; Yang and Yan, 2007). Cells (HepG2) were plated in 48-well plates in EMEM supplemented with $10 \%$ FBS at a density of $6 \times 10^{4}$ cells per well. Transfection was conducted by FuGene HD (Roche, Indianapolis, IN). Transfection mixtures contained $100 \mathrm{ng}$ of a PXR construct, $50 \mathrm{ng}$ of reporter plasmid CYP3A4-DP-Luc (Song et al., 2005), and 5 ng of TK-Renilla luciferase plasmid. Cells were transfected for $12 \mathrm{~h}$ and the medium was replaced with fresh medium supplemented with $1 \%$ delipided FBS. The treatment lasted for $24 \mathrm{~h}$ and the cells were washed once with phosphate buffered saline (PBS), lysed by addition of $50 \mu \mathrm{l}$ of passive lysis buffer with shaking at room temperature for $30 \mathrm{~min}$. The reporter enzyme activities were assayed with a Dual-Luciferase Reporter Assay System (Liu et al., 2008). This system contained two substrates, which were used to determine the activities of two luciferases sequentially. The firefly luciferase activity, which represented the reporter activity, was initiated by mixing an aliquot of lysates $(10 \mu \mathrm{l})$ with Luciferase Assay Reagent II. Then the firefly luminescence was quenched and the Renilla luminescence was simultaneously activated by adding Stop \& Glo Reagent to the sample tubes. The firefly luminescence signal was normalized based on the Renilla luminescence signal.

\section{Western analysis}

Microsomes or lysates were resolved by 7.5\% SDS-PAGE in a mini-gel apparatus and transferred electrophoretically to nitrocellulose membranes. After non-specific binding sites were blocked with $5 \%$ non-fat milk, the blots were incubated with an antibody against HCE1, HCE2, CYP3A4 or GAPDH. The preparation of the antibodies against HCE1, HCE2 or CYP3A4 was described elsewhere (Zhu et al., 2000; Xie et al., 2002). The primary antibodies were subsequently localized with goat anti-rabbit IgG conjugated with horseradish peroxidase. Horseradish peroxidase activity was detected with a chemiluminescent kit (SuperSignal West Pico). The chemiluminescent signal was captured by KODAK Image Station 2000 and the relative intensities were quantified by KODAK 1D Image Analysis Software.

Other analyses-Protein concentrations were determined with BCA assay (Pierce) based on albumin standard. Data are presented as mean $\pm \mathrm{SD}$ of at least three separate experiments, except where results of blots are shown in which case a representative experiment is depicted in the figures. Comparisons between two values were made with Student's test at $p<0.05$. Correlations analyses were performed with SPSS version 16 .

\section{RESULTS}

\section{Hydrolysis of a panel of pyrethroids by human liver microsomes}

Carboxylesterases play an important role in the metabolism of pyrethroids (Nishi et al., 2006; Ross et al., 2006). In rodents, it has been shown that hydrolysis offers critical protection against pyrethroid-induced toxicity (Cantalamessa, 1993). One of the objectives of this study was to determine whether there is a correlation between hydrolysis of various pyrethroids by human livers and the toxicity established in animals. Human liver microsomes were pooled and tested for the hydrolysis of 11 pyrethroids (Table I, Fig. 1). Selection of these pyrethroids was based on the structural diversity, the extent of use and their relative toxicity in rodents (Casida et al., 1983; Dich et al., 1997; Table I). These insecticides are currently registered for use without restriction (EPA, 2008). Some of the pyrethroids were previously studied for hydrolysis by other investigators (Nishi et al., 2006; Ross et al., 2006). All pyrethroids tested in this study (Table I) were purchased from ChemService and utilized without further 
purification. The hydrolysis was monitored by HPLC based on the disappearance of parent compounds. Under the experimental condition, all pyrethroids were eluted with a single peak except permethrin, baythroid and tetramethrin. Permethrin displayed two peaks with distinct retention time (RT=10.18, $10.41 \mathrm{~min}$ ) (Table I). In contrast, baythroid and tetramethrin produced two peaks, but these peaks were closely overlapped.

The results on the hydrolysis are summarized in Fig. 2. All pyrethroids were hydrolyzed by human liver microsomes, however, the extent of the hydrolysis varied by as many as 14 fold (Fig. 2). Bioresmethrin (Bior) was hydrolyzed to the highest extent, whereas bifenthrin (Bif) to the least. Overall, the insecticides could be divided into three groups based on the rates of hydrolysis. The group with a high rate included bioallethrin (Bioa), bioresmethrin, deltamethrin (Del) and tetramethrin (Tet); the group with a moderate rate included baythroid (bay) and lambda-cyhalothrin (Cyh); the group with a low rate included bifenthrin, esfenvalerate (Esf) and tau-fluvalinate (Tau) (Fig. 2). The rates of permethrin hydrolysis varied by more than 5 fold depending on an isomer (Fig. 2). The one with an RT of 10.18 min (Per-1) was hydrolyzed much faster than the one with an RT of $10.41 \mathrm{~min}$ (Per-2). As a matter of fact, the former (Per-1) belonged to the group that was hydrolyzed at a high rate, whereas the later (Per-2) belonged to the group hydrolyzed at a low rate. Permethrin consisted of $46 \%$ cis-isomer and $52 \%$ trans-isomer. Based on the peak areas and hydrolytic studies reported by other investigators (Nishi et al., 2006; Crow et al., 2007), the cis-isomer had an RT of 10.41, whereas the trans-isomer had an RT of 10.18 min.

\section{Differential hydrolysis of pyrethroids by HCE1 and HCE2}

We next tested the inter-individual variability in hydrolyzing pyrethroids. Ten individual microsomal samples were selected from a total of 19 donors (Shi et al., 2006), and the selection was based on the relative abundance of carboxylesterases HCE1 and HCE2, two major liver carboxylesterases (Satoh and Hosokawa, 2006). The study with individual donor samples was performed on the hydrolysis of bioallethrin. This pyrethroid, compared with others, has the similar size of the alcohol and acid moieties. The relative sizes of the alcohol and acid moieties of an ester have been suggested to contribute to selective hydrolysis by carboxylesterases (Shi et al., 2006). As shown in Fig. 3A, all individual samples hydrolyzed bioallethrin, and the overall hydrolysis varied by $\sim 2$-fold. We next tested whether the variation was correlated with the abundance of HCE1 or HCE2. The immuno-intensities of HCE1 or HCE2 were analyzed for the correlation with the hydrolytic rate of bioallethrin obtained by individual donor samples. As shown in Fig. 3B, the hydrolysis of bioallethrin was correlated much higher with HCE1 than HCE2 (correlation coefficients: 0.7935 versus 0.4519 , respectively).

The higher correlation with HCE1 suggests that this carboxylesterase is more active than HCE2 in hydrolyzing bioallethrin. To determine whether pyrethroids are differentially hydrolyzed by HCE1 and HCE2, recombinant HCE1 and HCE2 were assayed for the hydrolysis of this panel of pyretrhoids. We previously prepared insect cell lines stably expressing HCE1 or HCE2 (Zhu et al., 2000). Cell lysates were prepared from the respective lines and the abundance of HCE1 or HCE2 in the lysates was estimated according to immunostaining intensities generated with serial amounts of purified HCE1 and HCE2. Fig. 3C shows the specific activities of HCE1 and HCE2 toward each pyrethroid. HCE1 preferably hydrolyzed bioallethrin, bioresmethrin, deltamethrin, esfenvalerate and lambda-cyhalothrin. In contrast, HCE2 preferably hydrolyzed baythroid, bifenthrin, permethrin, tau-fluvalinate and tetramethrin. The extent of the preference, however, varied markedly. For example, HCE2 hydrolyzed cis-permethrin (Per-2) 7 times as fast as HCE1, but only 15\% faster in hydrolyzing trans-permethrin (Per-1) (Fig. 3C). In addition to the preference for hydrolysis, the overall hydrolytic rates were quite different from one pyrethroid to another. For example, both bioresmethrin and esfenvalerate were preferably hydrolyzed by HCE1, but bioresmethrin was hydrolyzed 7 times as fast as 
esfenvalerate (Fig. 3C). It should be noted that lysates from vector transfected line showed no evident hydrolysis toward the pyrethroids.

\section{Pyrethroids induce CYP3A4 but not carboxylesterases}

Some xenobiotics such as anticonvulsant carbamazepine increase their own metabolism through enzyme induction (Magnusson et al., 2007). Next we tested whether pyrethroids induce the expression of carboxylesterases. Human primary hepatocytes were treated with a pyrethroid $(10 \mu \mathrm{M})$ and the expression of HCE1 and HCE2 was monitored by RT-qPCR with Taqman probes. In addition to HCE1 and HCE2, the expression of CYP3A4 was also monitored. As shown in Fig. 4A, little changes $(<15 \%)$ were detected in the levels of HCE1 or HCE2 mRNA. However, the level of CYP3A4 mRNA was markedly increased in the hepatocytes treated with a pyrethroid, and the increase was statistically significant with all pyrethroids except tetramethrin (Fig. 4A). The maximum induction was 3.5 fold and occurred with lambdacyhalothrin. Baythroid, bifenthrin, esfenvalerate and tau-fluvalinate, along with lambdacyhalothrin, were relatively stronger CYP3A4 inducers (2.5 fold or higher) (Fig. 4A). Bioallethrin, bioresmethrin and tetramethrin were relatively weaker inducers, and the remaining pyrethroids caused moderate induction (Fig. 4A). Consistent with the RT-qPCR analyses, Western blotting detected a significant increase in CYP3A4 but not HCE1 or HCE2 protein in the hepatocytes treated with lambda-cyhalothrin (Fig. 4B). A slight increase in CYP3A4 protein was detected in the hepatocytes treated with tetramethrin (Fig. 4B).

We next examined whether the induction occurs in immortalized cell lines including HepG2 (hepatoma), Hop92 (lung carcinoma) and LS180 (colorectal adenocarcinoma). Hop92 and LS180 Cell were included because ingestion and inhalation are recognized to be two major routes of exposure to pyrethroids (Leng et al., 1997; Heudorf and Angerer, 2001). The cell lines were treated with esfenvalerate at $1 \mu \mathrm{M}$ instead of $10 \mu \mathrm{M}$. Similarly, total RNA was isolated and analyzed for the levels of CYP3A4 mRNA by RT-qPCR. As shown in Fig. 4C, significant induction of CYP3A4 was detected in all cell lines, and HepG2 cells supported higher induction than Hop92 or LS180 cells. Next we tested the induction as a function of various concentrations of esfenvalerate in HepG2 cells. As shown in Fig. 4C, the induction of CYP3A4 occurred in a concentration-dependent manner. Significant induction was detected when esfenvalerate was assayed at as low as $0.5 \mu \mathrm{M}$ (Fig. 4C).

To determine whether induction of CYP3A4 enhances the metabolism of pyrethroids, a pyrethroid was incubated with Supersomes containing recombinant CYP3A4, P450 reductase and b5 in the presence of the NRS system. As shown in Fig. 4D, bioallethrin and tetramethrin were metabolized by CYP3A4 to the greatest extent among the pyrethroids, whereas taufluvalinate was metabolized to the least extent. The remaining pyrethroids were comparably metabolized by CYP3A4. Several controls were performed including: zero-time incubation, exclusion of the NRS, and Supersomes expressing no P450. The metabolism was detected only with CYP3A4 Supersomes in the presence of the NRS. It should be noted that the metabolism of these pyrethroids by CYP3A4, compared with hydrolysis, is slow, suggesting that hydrolysis but not oxidation is the major pathway for the metabolism of these pyrethroids in humans.

\section{Activation of PXR by pyrethroids}

It is well established that PXR supports induction of CYP3A4 in response to a wide range of structurally diverse xenobiotics (Lemaire et al., 2004; Urquhart et al., 2007). Next we examined whether these pyrethroids are PXR activators, and more importantly whether the induction of CYP3A4 is correlated with the activation of PXR. We previously prepared a stable line constitutively expressing human PXR and harboring a PXR element reporter (Song et al., 2004). This line (hPXR-HER) was plated in 96 well-plates and the treatment started with a pyrethroid when cells reached $80 \%$ confluence. The luciferase activity was determined $24 \mathrm{~h}$ 
after the treatment and normalized according to protein concentrations. As shown in Fig. 5A, the activation pattern was generally similar as the induction of CYP3A4 among these pyrethroids (Fig. 4A). For example, lambda-cyhalothrin (Cyh) was the strongest inducer of CYP3A4 (Fig. 4A) and activated the PXR the most (Fig. 5A). Conversely, bioallethrin was one of the weaker inducers (Fig. 4A) and activated PXR with less potency (Fig. 5A).

On the other hand, there were several noticeable differences between CYP3A4 induction and the PXR activation in terms of the relative potency. For example, tau-fluvalinate and lambdacyhalothrin caused a comparable induction (3.2 versus 3.5 fold) (Fig. 4A), whereas lambdacyhalothrin was a stronger activator of PXR (6.3 versus 3.5 fold) (Fig. 5A). Actually, lambdacyhalothrin caused even higher activation than rifampicin (Rif) (Fig. 4A), a prototypical activator of human PXR (Chrencik et al., 2005). Another difference between the induction and activation was observed on tetramethrin. This pyrethroid caused only a minimal induction of CYP3A4 (Fig. 4A). Surprisingly, a 3.5-fold activation of PXR was detected (Figs. 5A). Such a large disparity was likely due to the difference in the capacity of hydrolysis between the hPXR-HER line and primary hepatocytes. The hPXR-HRE line was prepared with 293T cell and had no detectable hydrolytic activity toward pyrethroids, whereas primary hepatocytes expressed relatively high levels of carboxylesterases. Therefore, it was hypothesized that hydrolysis of tetramethrin markedly decreases its potency in PXR activation.

We next tested this hypothesis in cotransfection experiments. hPXR-HRE cells were transfected again with HCE1, HCE2 or the corresponding vector, and the transfected cells were tested for the activation of PXR by tetramethrin, lambda-cyhalothrin and deltamethrin. Inclusion of lambda-cyhalothrin and deltamethrin was designed to specify the isoform-based hydrolysis in decreased activation of PXR. As shown in Fig. 5B, cotransfection markedly decreased PXR activation by all three pyrethroids, and the decreases were in agreement with the isoform-dependent hydrolysis. For example, HCE1, much more active than HCE2 in hydrolyzing lambda-cyhalothrin and deltamethrin (Fig. 3C), caused much more decreases in PXR activation by these two pyrethroids (Fig. 5B). Conversely, HCE2, slightly more active than HCE1 in hydrolyzing tetramethrin (Fig. 3C), decreased more PXR activation than HCE1 (Fig. 5B). This observation was confirmed in a concentration-response experiment (5B). Tetramethrin at $1 \mu \mathrm{M}$ caused significant activation of PXR in the cells cotransfected by the vector, in contrast, as high as $5 \mu \mathrm{M}$ tetramethrin was required to cause significant activation in HCE1 co-transfected cells (Fig. 5B). Furthermore, none of the concentrations (even at 10 $\mu \mathrm{M})$ caused significant activation of PXR in HCE2-cotransfected cells (Fig. 5B). Western blotting confirmed the expression of HCE1 and HCE2 in respectively transfected cells (Fig. $5)$.

\section{Activation of human PXR variants and rat PXR by pyrethroids}

In humans, there exist several PXR polymorphic variants, and we have shown that some of the variants differed markedly from the wild-type PXR in responding to 8-methoxypsoralen and rifampicin (Yang and Yan, 2007). We next examined whether these variants respond differentially to pyrethroids. Cotransfection was performed with a PXR (wild type or a variant), a CYP3A4 promoter luciferase reporter (Song et al., 2005), and the Renilla plasmid. Three pyrethroids were tested including baythroid, esfenvalerate and lambda-cyhalothrin. Selection of these pyrethroids was based on the following considerations: baythroid was similar as lambda-cyhalothrin in the hydrolysis by human liver microsomes (Fig. 2), but differed in the potency of CYP3A4 induction and PXR activation (Fig. 4A and Fig. 5A). However, the opposite was true between baythroid and esfenvalerate (Fig. 2, Fig. 4A and Fig. 5A). As shown in Fig. 6A, all PXR variants responded similarly as the wild type PXR with a few exceptions. In some cases, the altered activation of PXR variants occurred similarly with all three pyrethroids. For example, variant L412I was activated by all three pyrethroids to a less extent 
than the wild-type PXR (Fig. 6A). In other cases, the magnitude of alteration varied depending on a pyrehroid. For examples, variant S208F was activated by baythroid to a much higher extent than the wild-type PXR (10.6 versus 5.7 fold), but no differences were detected in the activation in response to esfenvalerate or lambda-cyhalothrin (Fig. 6A).

It is well established that certain chemicals activate PXR in a species-dependent manner (Song et al., 2005). We next examined whether rat PXR is activated differentially from human PXR by this group of pyrethroids. Likewise, co-transfection was conducted to test this possibility. As shown in Fig. 6B, all pyrethroids activated rat PXR, but the overall activation varied from one pyrethroid to another. The highest activation was 4.5 fold and occurred with esfenvalerate and the lowest was 2.0 fold and occurred with bioallethrin (Fig. 6B). With human PXR, the lowest activation was 1.5 fold (bioresmethrin), whereas the highest activation was 6.3 fold (lambda-cyhalothrin) (Fig. 5A). Therefore, the activation of rat PXR varied less than that of human PXR in response to these pyrethroids. Another noticeable difference regarding PXR activation was the relative potency between lambda-cyhalothrin and esfenvalerate. The former was a stronger activator of human PXR (Fig. 5A), whereas the later was a stronger activator of rat PXR (Fig. 6B). As a matter of fact, esfenvalerate activated rat PXR comparably as PCN, a prototypical activator of rodent PXR (Fig. 6B) (Song et al., 2005). In addition, bifenthrin and permethrin, relatively weak activators of human PXR (Fig. 5A), but efficaciously activated rat PXR (Fig. 6B).

\section{DISCUSSION}

Pyrethroids represent the most used insecticides in the world and account for more than onethird of the insecticide market (Dich et al., 1997). In mammals, these insecticides undergo hydrolytic and oxidative metabolism, and hydrolysis provides critical protection against pyrethroid-induced toxicity (Cantalamessa, 1993). In this study, we have shown with a panel of pyrethroids that the magnitude of the hydrolysis varied by as many as 14 fold in human livers. Some pyrethroids such as esfenvalerate were hydrolyzed preferably by a carboxylesterases (e.g., HCE1 or HCE2), whereas others such as trans-permethrin were comparably hydrolyzed by both enzymes. In human primary hepatocytes, pyrethroids caused little changes in the expression of carboxylesterases. In contrast, the expression of CYP3A4 was significantly induced. Overall, the induction was positively correlated with the activation of PXR among pyrethroids. Transfection of a carboxylesterase markedly decreased PXR activation, and the decrease was in agreement with carboxylesterase-based preference for hydrolysis.

The isoform-based preference for hydrolysis likely serves as an indicator for the magnitude of the hydrolysis in the liver. HCE1 is a more abundant carboxylesterase than HCE2 in the liver, thus pyrethroids preferably hydrolyzed by HCE1 were generally hydrolyzed faster by liver microsomes (Fig. 2 and Fig. 3C). For example, bioallethrin, bioresmethrin and deltamethrin, preferable substrates of HCE1 (Fig. 3C), were all hydrolyzed efficaciously by liver microsomes (Fig. 2). Another indicator for the magnitude of hydrolysis is the Type of a pyrethroid. As a matter of fact, the Type of pyrethroids probably serves a better indicator for the overall hydrolysis in the liver. With only one exception (deltamethrin), all pyrethroids hydrolyzed at high rates by liver microsomes are Type I compounds (Table I, Fig. 1 and Fig. 2). Conversely, the majority of the pyrethroids hydrolyzed at lower rates belong to Type II compounds (e.g., tau-fluvalinate) (Table I, Fig. 1 and Fig. 2). An interesting exception was bifenthrin, which is a Type I compound but was hydrolyzed the least by liver microsomes among all pyrethroids tested (Fig. 1 and Fig. 2). It has been suggested that the poor hydrolysis of this pyrethroid is due to the rigidity of the acid moiety (a methyl biphenyl group) (Nishi et al., 2006). In this study, we have shown that lambda-cyhalothrin, with the same alcohol moiety (cyano-3phenoxybenzyl group) as bifenthrin (Fig. 1), was hydrolyzed at a moderate rate (Fig. 2), 
suggesting that the alcohol moiety, like the acid moiety, also contributes to the less effective hydrolysis.

The relative size of the acid and alcohol moieties of an ester has been suggested to be a factor for the hydrolytic preference between HCE1 and HCE2. This principle, however, does not quite apply to pyrethroids. Bioresmethrin, for example, has an acid moiety with a comparable size as the alcohol moiety (162 versus 174 , Fig. 1), but was hydrolyzed overwhelmingly by HCE1 (Fig. 3C). Pyrethroids are highly lipophilic, and the selective hydrolysis of such lipophilic substrates likely depends on the overall configuration other than the relative sizes between the acid and alcohol moieties. It should be noted that there are conflicting reports on the selective hydrolysis of deltamethrin. This study and a previous report by Godin et al. (2006) showed that deltamethrin was preferably hydrolyzed by HCE1. However, Nishi et al. (2006) reported that this pyrethroid was a better substrate of HCE2. All three studies were performed in Tris- $\mathrm{HCl}$ buffer, but the study by Nichi et al used higher $\mathrm{pH}$ (8.0 versus 7.4). It is likely that HCE2 works better at higher $\mathrm{pH}$, particularly with lipophilic substrates.

The magnitude of hydrolysis likely determines the overall toxicity of pyrethroids, particularly the lethal potency. Table I shows the $\mathrm{LD}_{50}$ values for these compounds in rats, ranging from $26 \mathrm{mg} / \mathrm{kg}$ (tau-fluvalinate) to $4640 \mathrm{mg} / \mathrm{kg}$ (tetramethrin). Consistent with such a large difference in the $\mathrm{LD}_{50}$ values, tetramethrin was hydrolyzed 9 times as fast as tau-fluvalinate by human liver microsomes (Fig. 2). These findings suggest that these pyrethroids are hydrolyzed comparably in both humans and rats. While the hydrolytic rates are generally correlated with their $\mathrm{LD}_{50}$ values, there were notable exceptions. For example, bioallethrin was hydrolyzed 8 times as fast as bifenthrin (Fig. 2), however, bifenthrin is less toxic than bioallethrin based on the $\mathrm{LD}_{50}$ values $(545$ versus $425 \mathrm{mg} / \mathrm{kg}$, Table I). It is likely that bifenthrin is effectively hydrolyzed by rat carboxylesterases. Alternatively, other metabolic pathways such as oxidation contribute significantly to the detoxication of bifenthrin in rats.

The activation potential of PXR, along with the magnitude of hydrolysis, appears to play determinant roles in CYP3A4 induction. Bioallethrin, bioresmethrin and tetramethrin were rapidly hydrolyzed, thus caused the least induction of CYP3A4 among the pyrethroids (Fig. 2, Fig. 3C and Fig. 4A). In contrast, lambda-cyhalothrin and tau-fluvalinate were hydrolyzed to a much less extent, thus caused much higher induction (Fig. 2 and Fig. 4A). On the other hand, baythroid was hydrolyzed 3 times as fast as bifenthrin and yet caused higher induction of CYP3A4 (Fig. 2, Fig. 3C and Fig. 4A). Such discrepancy was likely due to their difference in the potency of PXR activation. Indeed, bifenthrin was a much weaker PXR activator than baythroid (1.7 versus 3.3, Fig. 5A). It should be noted that the activation of human PXR was performed in the hPXR-HRE line, and this line showed no detectable hydrolytic activity toward pyrethroids.

The cotransfection of the hPXR-HRE line by a carboxylesterases provided a nice illustration on how hydrolysis and activation of PXR coordinate in the induction of CYP3A4. In primary hepatocytes, tetramethrin was the weakest CYP3A4 inducer (Fig. 4A). This pyrethroid, however, was one of the stronger PXR activators in the hPXR-HRE line (Fig. 5A). The efficacious activation of PXR by tetramethrin was markedly decreased by HCE1 or HCE2 cotransfection (Fig. 5B). The decrease was higher by HCE2 than HCE1, consistent with the observation that HCE2 hydrolyzed tetramethrin at a slightly higher rate than HCE1 (Fig. 3C). The importance of the hydrolysis in PXR activation likely provides a molecular basis for pesticide-pesticide interaction, particularly between pyrethroids and organophosphates. Organophosphates irreversibly inhibit carboxylesterases (Pope et al., 2005) and presumably decrease the hydrolysis of pyrethroids. Therefore, combined use of a pyrethroid and an organophosphate could increase the potential of pyrethroids in PXR activation and CYP induction. 
The efficacious activation of PXR by some of the pyrethroids ranks these chemicals as one of the most potent classes of PXR activators. In this study, we have shown that lambda-cyhalothrin caused even higher activation of human PXR than rifampicin (Fig. 5A), a prototypical activator of human PXR (Chrencik et al., 2005). Interestingly, with only a single exception of tetramethrin, pyrethroids with higher PXR activation activity all belong to Type II pyrethroids, suggesting that the cyano moiety facilitates interaction with PXR. In addition, the Type II pyrethroids all contain a phenoxybenzyl group (Fig. 1), which, along with the cyano moiety, forms a bulky and lipophilic platform. Such structure presumably increases the specificity to interact with the ligand binding pocket of PXR. In addition, these chemicals differentially activated certain polymorphic variants of human PXR (Fig. 6A). For example, PXR variant S208F was activated much higher than the wild type PXR (10.6 versus 5.7 fold) (Fig. 6A). Likewise, significant difference in the activation of human and rat PXR was detected on the relative potency between lambda-cyhalothrin and esfenvalerate. Lambda-cyhalothrin was a stronger activator of human PXR, whereas esfenvalerate was a stronger activator of rat PXR (Fig. 5A and Fig. 6B). Likewise, bifenthrin and permethrin were relatively weak activators of human PXR (Fig. 5A) but efficaciously activated rat PXR (Fig. 6B). These findings suggest that induction of PXR target genes by pyrethroids occur in a species- and polymorphismdependent manner.

The activation of PXR by pyrethroids likely contributes significantly to their toxicity, particularly related to chronic exposure. In addition to neurotoxicity, pyrethroids are increasingly linked to other organ toxicities such as reproduction (Perry et al., 2007). The reproductive toxicity is likely due to their partial antagonistic activity toward the estrogen or androgen receptors (Chen et al., 2002; Sun et al., 2007). On the other hand, hormones such as testosterones are metabolized by CYP enzymes (Choi et el., 2005). In this study, we have shown that esfenvalerate at $0.5 \mu \mathrm{M}$ significantly induced CYP3A4 (Fig. 4C). Therefore, induction of enzymes that metabolize hormones likely serves as an alternative mechanism for pyrethroidsinduced reproductive toxicity. As a class of the most used insecticides in the world, both the general population and workers have a potential of high exposure to these insecticides.

Epidemiological studies have shown that the exposure level, in some cases, can be high (Leng et al., 1997; Heudorf and Angerer, 2001). The concentrations of pyrethroid metabolites in the urine are usually monitored as a marker for exposure. Given the fact that pyrethroids undergo metabolism and not all pyrethroids in the body are eliminated through the urine (Leng et al., 1997; Anand et al., 2006; Godin et al., 2007), the urinary metabolites-based estimation is likely lower than the actual exposure level. Furthermore, the local concentrations in the entries such as the skin and the lung can be considerably higher even than the corresponding blood concentrations of exposed pyrethroids.

In summary, our work points to several important conclusions. First, the overall hydrolysis by liver microsomes varies depending on the Type of pyrethroids and the isoform-preference for hydrolysis. Given the observation that hydrolysis provides critical protection against pyrethroids-induced toxicity, the Type of pyrethroids and the preference for hydrolysis likely serve as indicators for toxicological predication in humans. Second, significant induction of CYP3A4 is detected at sub-micromolar concentrations of pyrethroids, providing a sensitive biomarker for pyrethroid exposure. Third, the induction of CYP3A4 is correlated positively with the activation of PXR and the activation varies between human and rat PXRs as well as among human PXR polymorphic variants, suggesting that induction of PXR target genes by pyrethroids occurs in a polymorphism and species-dependent manner.

\section{REFERENCE}

Adelsbach TL, Tjeerdema RS. Chemistry and fate of fenvalerate and esfenvalerate. Rev Environ Contam Toxicol 2003;176:137-154. [PubMed: 12442505] 
Anand SS, Kim KB, Padilla S, Muralidhara S, Kim HJ, Fisher JW, Bruckner JV. Ontogeny of hepatic and plasma metabolism of deltamethrin in vitro: role in age-dependent acute neurotoxicity. Drug Metab Dispos 2006;34:389-397. [PubMed: 16326812]

Cantalamessa F. Acute toxicity of two pyrethroids, permethrin, and cypermethrin in neonatal and adult rats. Arch Toxicol 1993;67:510-513. [PubMed: 8240001]

Casida JE, Gammon DW, Glickman AH, Lawrence LJ. Mechanisms of selective action of pyrethroid insecticides. Annu Rev Pharmacol Toxicol 1983;23:413-438. [PubMed: 6347050]

Casida JE, Quistad GB. Golden age of insecticide research: past, present, or future? Annu Rev Entomol 1998;43:1-16. [PubMed: 9444749]

Chen H, Xiao J, Hu G, Zhou J, Xiao H, Wang X. Estrogenicity of organophosphorus and pyrethroid pesticides. J Toxicol Environ Health A 2002;65:1419-1435. [PubMed: 12396874]

Choi MH, Skipper PL, Wishnok JS, Tannenbaum SR. Characterization of testosterone 11 betahydroxylation catalyzed by human liver microsomal cytochromes P450. Drug Metab Dispos 2005;33:714-718. [PubMed: 15764715]

Chrencik JE, Orans J, Moore LB, Xue Y, Peng L, Collins JL, Wisely GB, Lambert MH, Kliewer SA, Redinbo MR. Structural disorder in the complex of human pregnane $\mathrm{X}$ receptor and the macrolide antibiotic rifampicin. Mol Endocrinol 2005;19:1125-1134. [PubMed: 15705662]

Crow JA, Borazjani A, Potter PM, Ross MK. Hydrolysis of pyrethroids by human and rat tissues: examination of intestinal, liver and serum carboxylesterases. Toxicol Appl Pharmacol 2007;221:112. [PubMed: 17442360]

Dayal M, Parmar D, Dhawan A, Ali M, Dwivedi UN, Seth PK. Effect of pretreatment of cytochrome P450 (P450) modifiers on neurobehavioral toxicity induced by deltamethrin. Food Chem Toxicol 2003;41:431-437. [PubMed: 12504175]

Delescluse C, Ledirac N, de Sousa G, Pralavorio M, Lesca P, Rahmani R. Cytotoxic effects and induction of cytochromes P450 1A1/2 by insecticides, in hepatic or epidermal cells: binding capability to the Ah receptor. Toxicol Lett 1998;96-97:33-39.

Dich J, Zahm SH, Hanberg A, Adami HO. Pesticides and cancer. Cancer Causes Control 1997;8:420 443. [PubMed: 9498903]

Elliott M. Properties and applications of pyrethroids. Environ Health Perspect 1976;14:1-2. [PubMed: 789056]

El-Tawil OS, Abdel-Rahman MS. The role of enzyme induction and inhibition on cypermethrin hepatotoxicity. Pharmacol Res 2001;44:33-40. [PubMed: 11428908]

EPA. 2008. http://www.epa.gov/pesticides/reregistration/status_page_r.htm

Godin SJ, Scollon EJ, Hughes MF, Potter PM, DeVito MJ, Ross MK. Species differences in the in vitro metabolism of deltamethrin and esfenvalerate: differential oxidative and hydrolytic metabolism by humans and rats. Drug Metab Dispos 2006;34:1764-1771. [PubMed: 16855054]

Godin SJ, Crow JA, Scollon EJ, Hughes MF, DeVito MJ, Ross MK. Identification of rat and human cytochrome $\mathrm{p} 450$ isoforms and a rat serum esterase that metabolize the pyrethroid insecticides deltamethrin and esfenvalerate. Drug Metab Dispos 2007;35:1664-1671. [PubMed: 17576809]

Heder AF, Hirsch-Ernst KI, Bauer D, Kahl GF, Desel H. Induction of cytochrome P450 2B1 by pyrethroids in primary rat hepatocytes cultures. Biochem Pharmacol 2001;62:71-79. [PubMed: 11377398]

Heudorf U, Angerer J. Metabolites of pyrethroid insecticides in urine specimens: current exposure in an urban population in Germany. Environ Health Perspect 2001;109:213-217. [PubMed: 11333180]

Johri A, Yadav S, Singh RL, Dhawan A, Ali M, Parmar D. Long lasting effects of prenatal exposure to deltamethrin on cerebral and hepatic cytochrome P450s and behavioral activity in rat offspring. Eur J Pharmacol 2006;544:58-68. [PubMed: 16859670]

Lemaire G, de Sousa G, Rahmani R. A PXR reporter gene assay in a stable cell culture system: CYP3A4 and CYP2B6 induction by pesticides. Biochem Pharmacol 2004;68:2347-2358. [PubMed: 15548381]

Leng G, Kühn KH, Idel H. Biological monitoring of pyrethroids in blood and pyrethroid metabolites in urine: applications and limitations. Sci Total Environ 1997;199:173-181. [PubMed: 9200861] 
Liu F, Yang D, Song X, Deng R, Yan B. The far and distal enhancers in the CYP3A4 gene coordinates the proximal promoter in responding to the pregnane $\mathrm{X}$ receptor similarly but differentially to hepatocyte nuclear factor-4 $\alpha$. Biochem J 2008;409:243-250. [PubMed: 17764444]

Ma Y, Sachdeva K, Liu J, Ford M, Yang D, Khan IA, Chichester CO, Yan B. Desmethoxy-yangonin and dihydromethysticin are two major pharmacological kavalactones with marked activity on the induction of CYP3A23. Drug Metab Dispos 2004;32:1317-1324. [PubMed: 15282211]

Magnusson MO, Dahl ML, Cederberg J, Karlsson MO, Sandström R. Pharmacodynamics of carbamazepine-mediated induction of CYP3A4, CYP1A2, and Pgp as assessed by probe substrates midazolam, caffeine, and digoxin. Clin Pharmacol Ther 2008;84:52-62. [PubMed: 17971810]

Nishi K, Huang H, Kamita SG, Kim IH, Morisseau C, Hammock BD. Characterization of pyrethroid hydrolysis by the human liver carboxylesterases hCE-1 and hCE-2. Arch Biochem Biophys 2006;445:115-123. [PubMed: 16359636]

Perry MJ, Venners SA, Barr DB, Xu X. Environmental pyrethroid and organophosphorus insecticide exposures and sperm concentration. Reprod Toxicol 2007;23:113-118. [PubMed: 17011162]

Pope CN, Karanth S, Liu J, Yan B. Comparative carboxylesterase activities in infant and adult liver and their in vitro sensitivity to chlorpyrifos oxon. Regul Toxicol. Pharm 2005;42:62-69.

Price RJ, Giddings AM, Scott MP, Walters DG, Capen CC, Osimitz TG, Lake BG. Effect of Pyrethrins on cytochrome P450 forms in cultured rat and human hepatocytes. Toxicology 2007;243:84-95. [PubMed: 18022748]

Ross MK, Borazjani A, Edwards CC, Potter PM. Hydrolytic metabolism of pyrethroids by human and other mammalian carboxylesterases. Biochem Pharmacol 2006;71:657-669. [PubMed: 16387282]

Satoh T, Hosokawa M. Structure, function and regulation of carboxylesterases. Chem Biol Interact 2006;162:195-211. [PubMed: 16919614]

Shi D, Yang J, Yang D, LeCluyse EL, Black C, You L, Akhlaghi F, Yan B. Anti-influenza prodrug oseltamivir is activated by carboxylesterase human carboxylesterase 1 , and the activation is inhibited by antiplatelet agent clopidogrel. J Pharmacol Exp Ther 2006;319:1477-1484. [PubMed: 16966469]

Soderlund DM, Knipple DC. The molecular biology of knockdown resistance to pyrethroid insecticides. Insect Biochem Mol Biol 2003;33:563-577. [PubMed: 12770575]

Song X, Xie M, Zhang H, Li Y, Sachdeva K, Yan B. The pregnane X receptor binds to response elements in a genomic context-dependent manner and its activator rifampicin selectively alters the bindings among target genes. Drug Metab Dispos 2004;32:35-42. [PubMed: 14709618]

Song X, Li Y, Liu J, Mukundan M, Yan B. Simultaneous substitution of phenylalaine-305 and aspartate-318 of rat PXR by the corresponding human residues abolishes the ability to transactivate the cytochrome P4503A23 promoter. J Pher Exp Ther 2005;312:571-582.

Sun H, Xu XL, Xu LC, Song L, Hong X, Chen JF, Cui LB, Wang XR. Antiandrogenic activity of pyrethroid pesticides and their metabolite in reporter gene assay. Chemosphere 2007;66(3):474-479. [PubMed: 16857237]

Tang M, Mukundan M, Yang J, Charpentier N, LeCluyse EL, Black C, Yang D, Shi D, Yan B. Antiplatelet agents aspirin and clopidogrel are hydrolyzed by distinct carboxylesterases, and clopidogrel is transesterificated in the presence of ethyl alcohol. J Pharmacol Exp Ther 2006;319:1467-1476. [PubMed: 16943252]

Urquhart BL, Tirona RG, Kim RB. Nuclear receptors and the regulation of drug-metabolizing enzymes and drug transporters: implications for interindividual variability in response to drugs. J Clin Pharmacol 2007;47:566-578. [PubMed: 17442683]

Vais H, Williamson MS, Devonshire AL, Usherwood PN. The molecular interactions of pyrethroid insecticides with insect and mammalian sodium channels. Pest Manag Sci 2001;57:877-888. [PubMed: 11695180]

Wolansky MJ, Harrill JA. Neurobehavioral toxicology of pyrethroid insecticides in adult animals: a critical review. Neurotoxicol Teratol 2008;30:55-78. [PubMed: 18206347]

Xie M, Yang D, Liu L, Xue B, Yan B. Human and rodent carboxylesterases: immunorelatedness, overlapping substrate specificity, differential sensitivity to serine enzyme inhibitors, and tumorrelated expression. Drug Metab Dispos 2002;30:541-547. [PubMed: 11950785] 
Yang J, Yan B. Photochemotherapeutic agent 8-methoxypsoralen induces cytochrome P450 3A4 and carboxylesterase HCE2: evidence on an involvement of the pregnane $\mathrm{X}$ receptor. Toxicol Sci 2007;95:13-22. [PubMed: 17003103]

Yang J, Shi D, Yang D, Song X, Yan B. Interleukin-6 suppresses the expression of carboxyl-esterases HCE1 and HCE2 through transcriptional repression. Mol Pharmacol 2007;72:686-694. [PubMed: 17537833]

Zhang H, LeCluyse E, Liu L, Hu M, Matoney L, Yan B. Rat pregnane X receptor: molecular cloning, tissue distribution and xenobiotic regulation. Arch Biochem Biophys 1999;368:14-22. [PubMed: 10415106]

Zhu W, Song L, Zhang H, Matoney L, LeCluyse E, Yan B. Dexamethasone differentially regulates expression of carboxylesterase genes in humans and rats. Drug Metab Dispos 2000;28:186-191. [PubMed: 10640517]

\section{Acknowledgments}

This work was supported by NIH grants R01ES07965 and R01GM61988.

The authors thank Dr. Robert Rodgers of the University of Rhode Island for critical reading of the manuscript.

\section{Abbreviations}

CYP, cytochrome P450

EMEM, Eagle's minimum Essential medium

FBS, Fetal bovine serum

GAPDH, glyceradehyde-3-phosphate dehydrogenase

HCE, human carboxylesterase

HPLC, high performance liquid chromatography

IS, internal standard

$\mathrm{LD}_{50}$, the median lethal dose

NRS, NADPH-regenerating system

PBS, phosphate buffered saline

PCN, pregnenolone 16 $\alpha$-carbonitrle

PXR, pregnane $\mathrm{X}$ receptor

$\mathrm{RT}$, retention time

RT-qPCR, reverse transcription-quantitative polymerase chain reaction

WME, William's medium E 


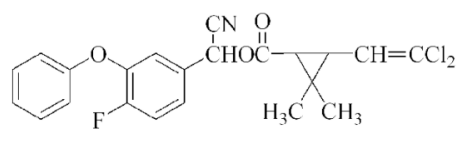

Baythroid (Type II): MW=434.31

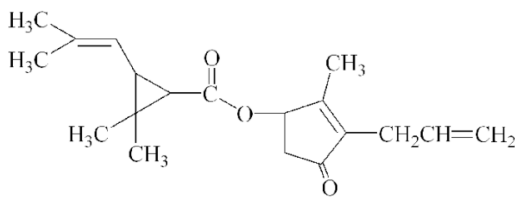

Bioallethrin (Type I): MW=302.4

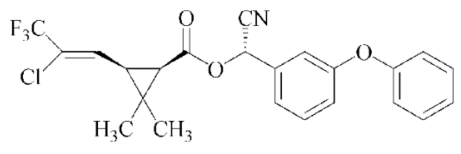

Lambda-Cyhalothrin (Type II): MW=449.88
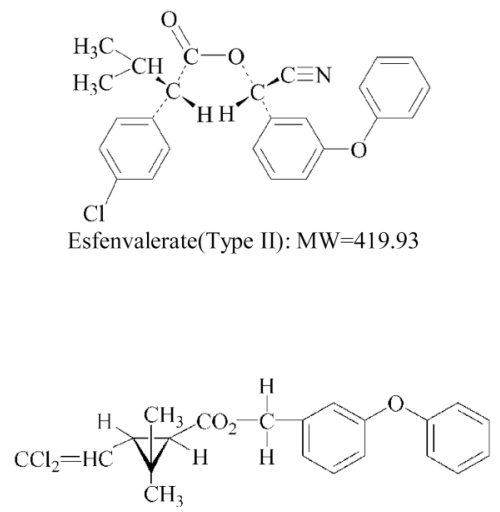

trans-Permethrin (Type I): MW=391.31

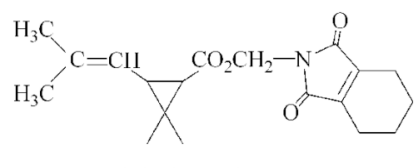

Tetramethrin (Type I): MW=331.45

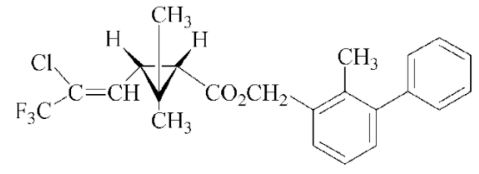

Bifenthrin (Type I): MW=422.90
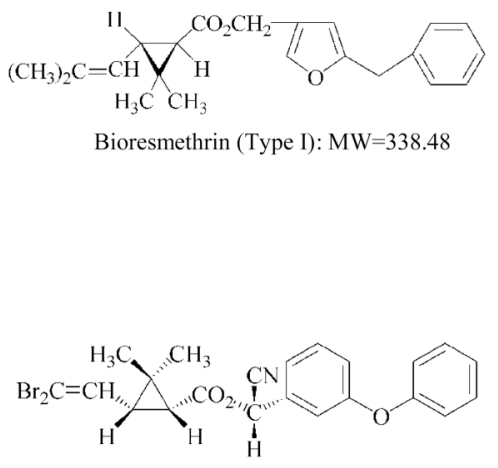

Deltamethrin $($ Type II): MW=505.24
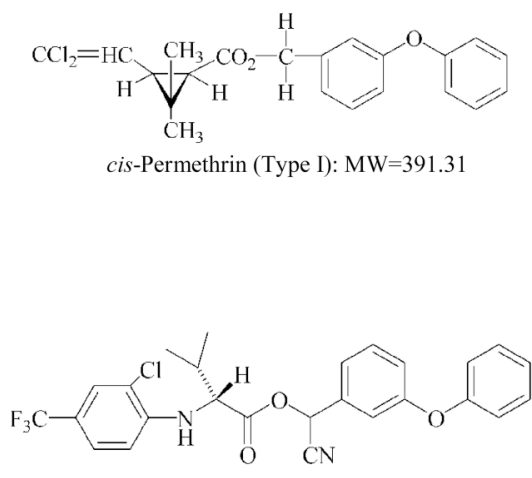

tau-Fluvalinate $($ Type II): MW=502.95

Fig. 1. Chemical structure of pyrethroids

Based on the absence or presence of the cyano moiety in the $\alpha$-position, a chemical with the cyano moiety is labeled as Type II, whereas a chemical without this moiety is labeled as Type I pyrethroid. 


\section{Hydrolysis by pooled human microsomes}

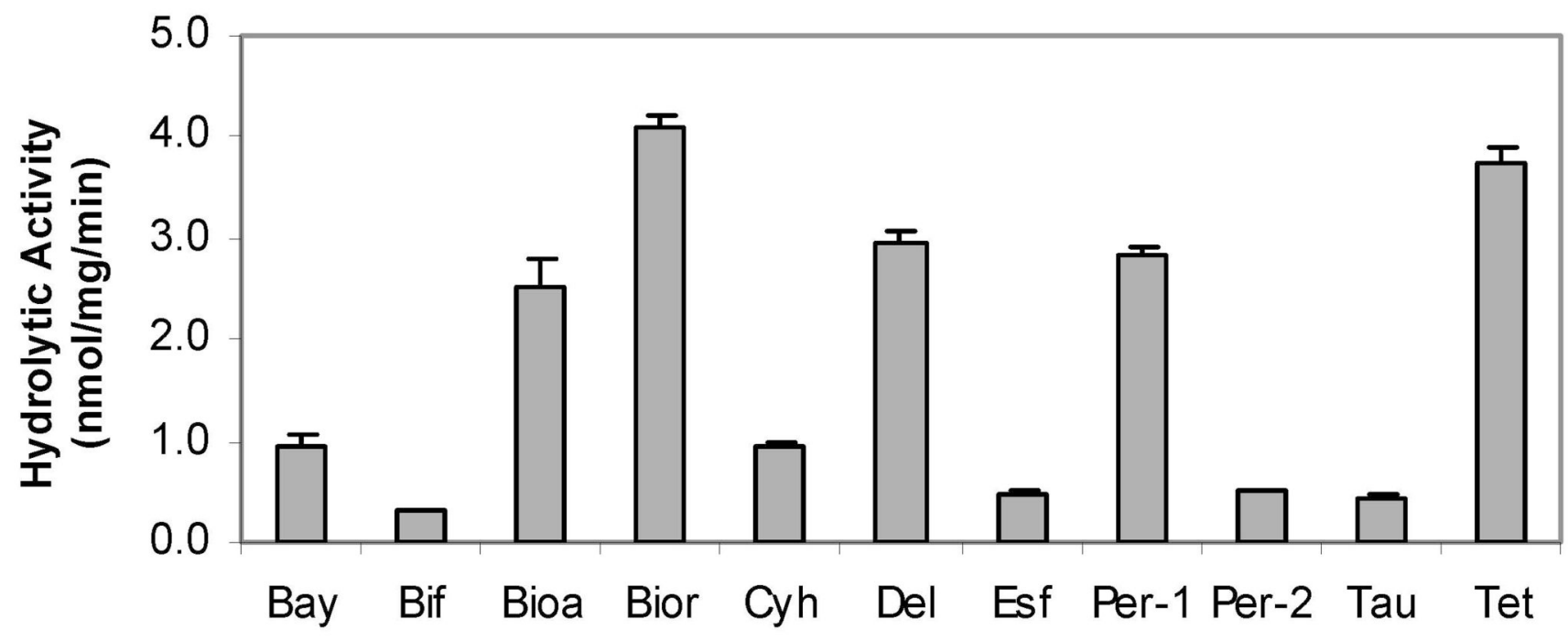

Bay $=$ baythroid, Bif $=$ bifenthrin, Bioa $=$ bioallethrin, Bior $=$ Bioresmethrin, Cyh = lambda-cyhalothrin, Del = deltamethrin, Esf $=$ esfenvalerate, Per-1 = trans- permethrin, Per-2 = cis-permethrin, $\mathrm{Tau}=$ tau-fluvalinate, $\mathrm{Tet}=$ tetramethrin

Fig. 2. Hydrolysis of pyrethroids by pooled human liver microsomes

Samples $(50 \mu \mathrm{g}$ protein) were prepared in $75 \mu \mathrm{l}$ Tris- $\mathrm{HCl}$ buffer $(50 \mathrm{mM}, \mathrm{pH} 7.4)$ and then mixed with an equal volume of a pyrethroid $(200 \mu \mathrm{M})$ in the same buffer. The incubations lasted for 30-60 min depending on a pyrethroid and the reactions were terminated with $300 \mu 1$ of acetonitrile containing naproxen $(2 \mu \mathrm{g} / \mathrm{ml})$ or clopidogrel $(16 \mu \mathrm{g} / \mathrm{ml})$ as the IS. The reaction mixtures were subjected to centrifugation for $15 \mathrm{~min}$ at $4^{\circ} \mathrm{C}(15,000 \mathrm{~g})$ to remove proteins. The hydrolysis of pyrethroids was monitored by HPLC as described in the section of Materials and Methods. Hydrolytic rates were expressed as the mean $\pm \mathrm{SD}(\mathrm{nmol} / \mathrm{mg} / \mathrm{min})$ from three independent experiments. 
A

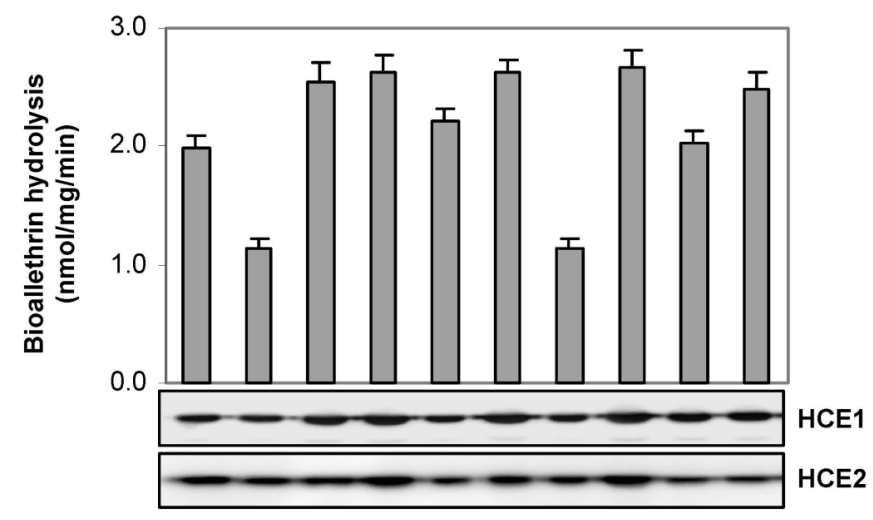

B
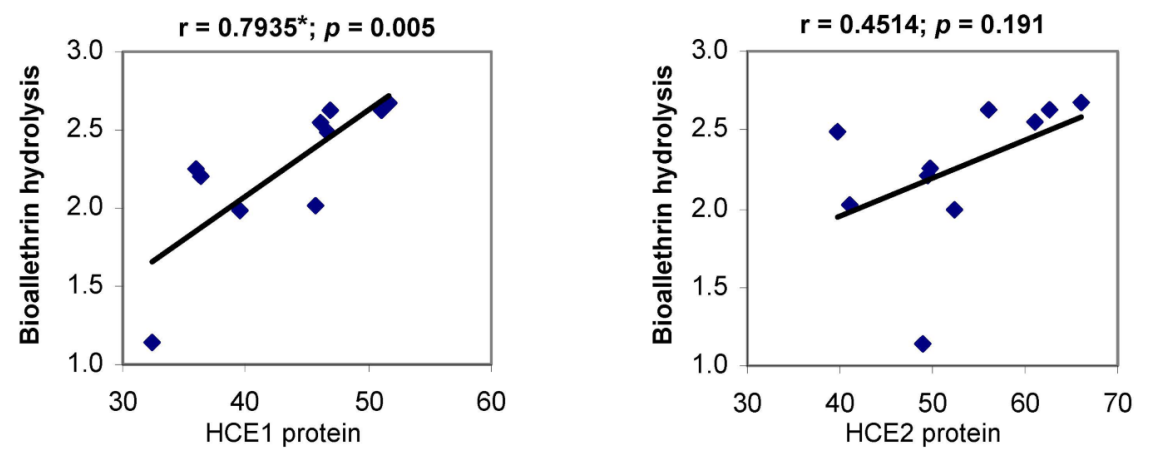

C

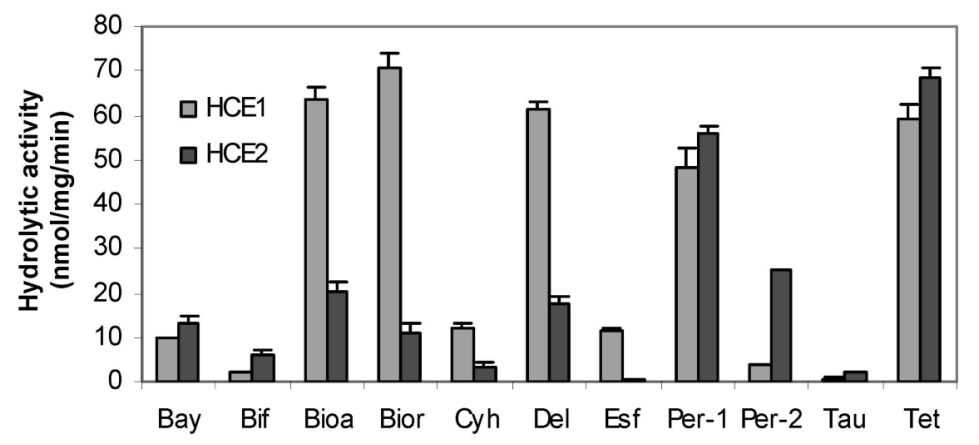

Fig. 3. Isoform-specific hydrolysis of pyrethroids

(A) Hydrolysis of bioallethrin by individual donor samples Enzymatic reactions were set up with $50 \mu \mathrm{g}$ microsomal protein and $100 \mu \mathrm{M}$ bioallethrin. The reactions lasted for $30 \mathrm{~min}$ and the hydrolysis of bioallethrin was monitored by HPLC. For Western blots, samples $(1 \mu \mathrm{g})$ were subjected to SDS-PAGE and transferred electrophoretically to a Trans-Blot nitrocellulose membrane. The immunoblots were incubated with the antibody $(10 \mu \mathrm{g} / \mathrm{ml})$ against HCE1, HCE2 or GAPDH and detected by horseradish peroxidase- conjugated anti-rabbit IgG and a chemiluminescent kit. The immunostaining intensity was quantified by KODAK 1D Image Analysis Software. (B) Correlation analysis of bioallethrin hydrolysis with HCE1 or HCE2 The hydrolysis of bioallethrin by individual donor samples was plotted against the 
corresponding immunointensity of HCE1 or HCE2. (C) Hydrolysis of pyrethroids by recombinant HCE1 or HCE2 Enzymatic reactions were set up as described in the legend of Fig. 1 but insect cell lysates from HCE1 or HCE2 stable lines were used. The hydrolytic rates were calculated according to the estimated HCE1 or HCE2 in the lysates. 
A

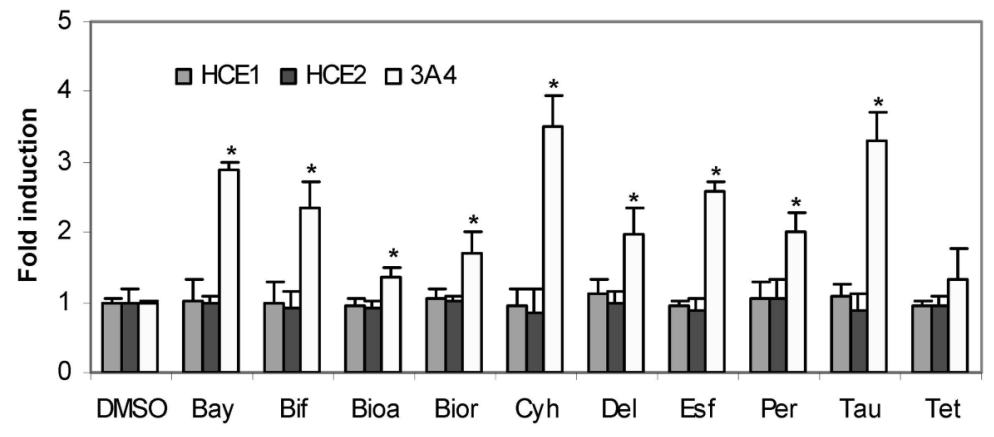

B

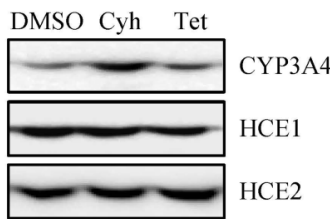

C
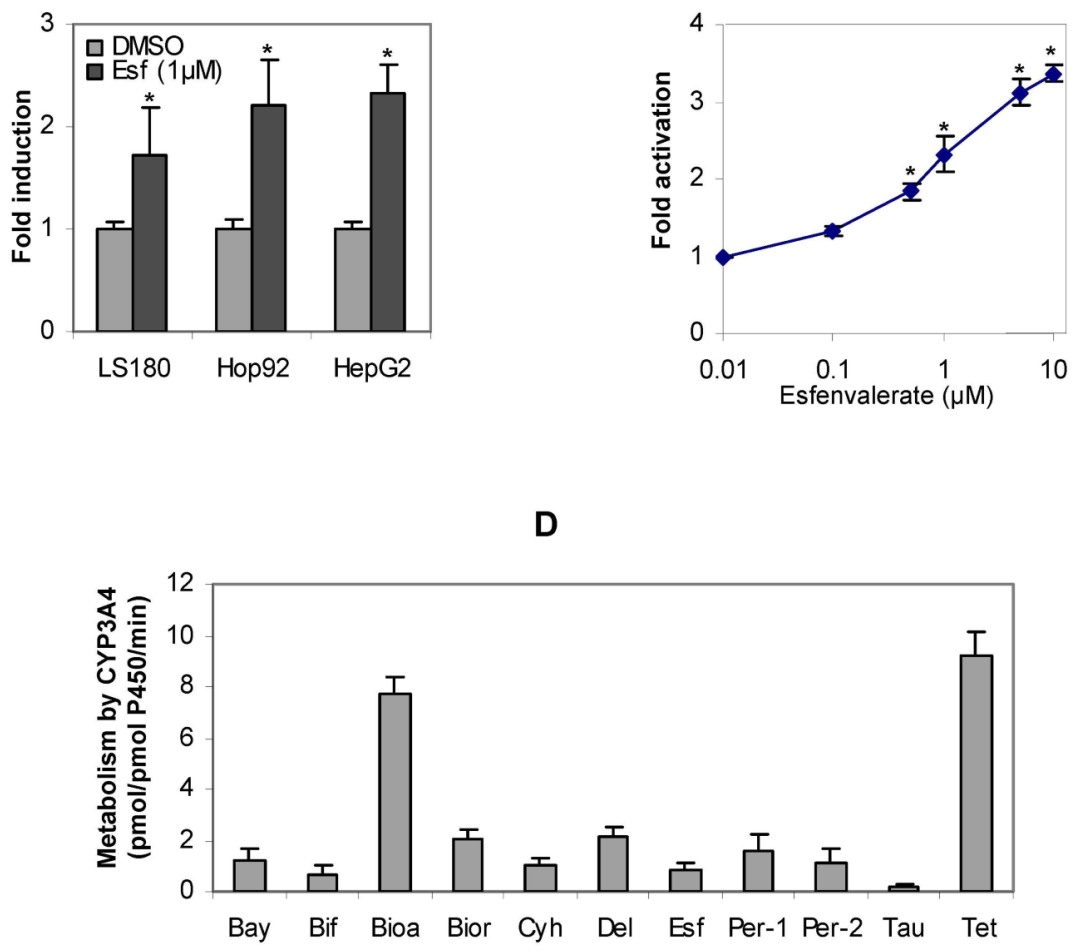

Fig. 4. Effect of pyrethroids on the levels of HCE1, HCE2, and CYP3A4 mRNA in primary hepatocytes or cell lines

(A) Effect of pyrethroids on the levels of HCE1, HCE2, and CYP3A4 mRNA in primary hepatocytes Human primary hepatocytes were treated with a pyrethroid $(10 \mu \mathrm{M})$ or the same volume of vehicle DMSO for $24 \mathrm{~h}$. Total RNAs were isolated and subjected to RT-qPCR analysis for the level of HCE1, HCE2, or CYP3A4 mRNA by TaqMan probes as described under Materials and Methods. The signals from each target were normalized based on the signal from GADPH, and data are expressed as mean \pm S.D. of four donors. (B) Western analysis for the expression of HCE1, HCE2 or CYP3A4 Lysates $(5 \mu \mathrm{g})$ from hepatocytes treated with DMSO, lambda-cyhalothrin (Cyh) or tetramethrin (Tet) were SDS-PAGE and transferred 
electrophoretically to a Trans-Blot nitrocellulose membrane. The immunoblots were incubated with the antibody $(10 \mu \mathrm{g} / \mathrm{ml})$ against HCE1, HCE2 or CYP3A4 and detected by horseradish peroxidase- conjugated anti-rabbit IgG and a chemiluminescent kit. The immunostaining intensity was quantified by KODAK 1D Image Analysis Software. (C) Effect of esfenvalerate on the level of CYP3A4 mRNA in HepG2, Hop 92 and LS180 cell lines Cells at $80 \%$ confluence were treated with esfenvalerate $(1 \mu \mathrm{M})$ for $24 \mathrm{~h}$. Total RNA was isolated and analyzed for the level of CYP3A4 mRNA by RT-qPCR. The mRNA levels were expressed relatively to those in control cells (considered as 1). To determine the concentrations-dependent induction, HepG2 cells were plated and treated with esfenvalerate at various concentrations $(0-10 \mu \mathrm{M})$. After 24-h, total RNA was isolated and analyzed for the level of CYP3A4 mRNA. The DMSO control is labeled as $0.01 \mu \mathrm{M}$ to accommodate logarithmic conversions of the data. *Statistically significant from vehicle control ( $\mathrm{p}<0.05$ ). (D) Metabolism of pyrethroids by CYP3A4 The incubation reactions were performed in a total volume of $100 \mu$. The reaction mixtures contained Supersomes (5 pmol P450) co-expressing P450 reductase and b5, potassium phosphate buffer (50 mM, pH 7.4), $\mathrm{MgCl}_{2}(3 \mathrm{mM})$, EDTA(1 mM), and a pyrethroid $(50 \mu \mathrm{M})$. Reactions were initiated by the addition of the NRS, placed in a shaking incubator at $37^{\circ} \mathrm{C}$, and terminated by the addition of $200 \mu \mathrm{l}$ of acetonitrile containing appropriate IS after 10 to 60 min depending on a pyrethroid. The reaction mixtures were subjected to centrifugation for $15 \mathrm{~min}$ at $4^{\circ} \mathrm{C}(15,000 \mathrm{~g})$ to remove proteins. The oxidation of pyrethroids was monitored by HPLC as described in the section of Materials and Methods. The rates were expressed as the mean \pm SD (pmol/pmol P450/min) from three independent experiments. 
A

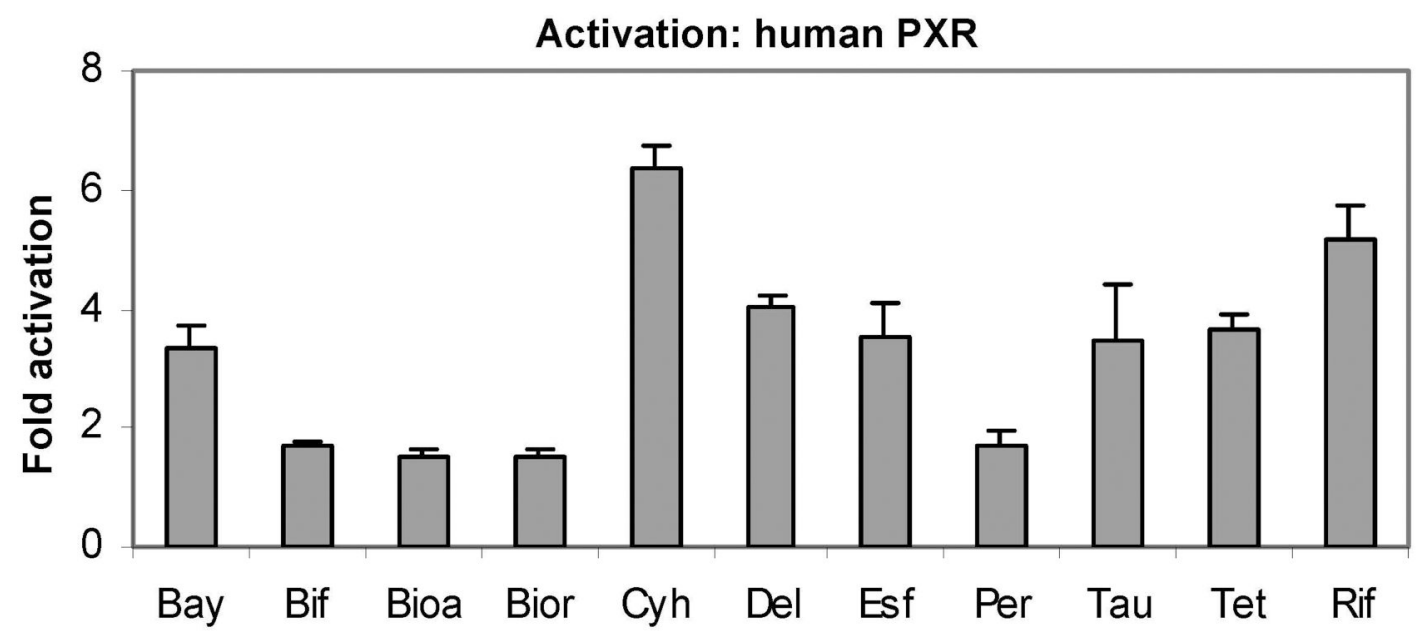

B
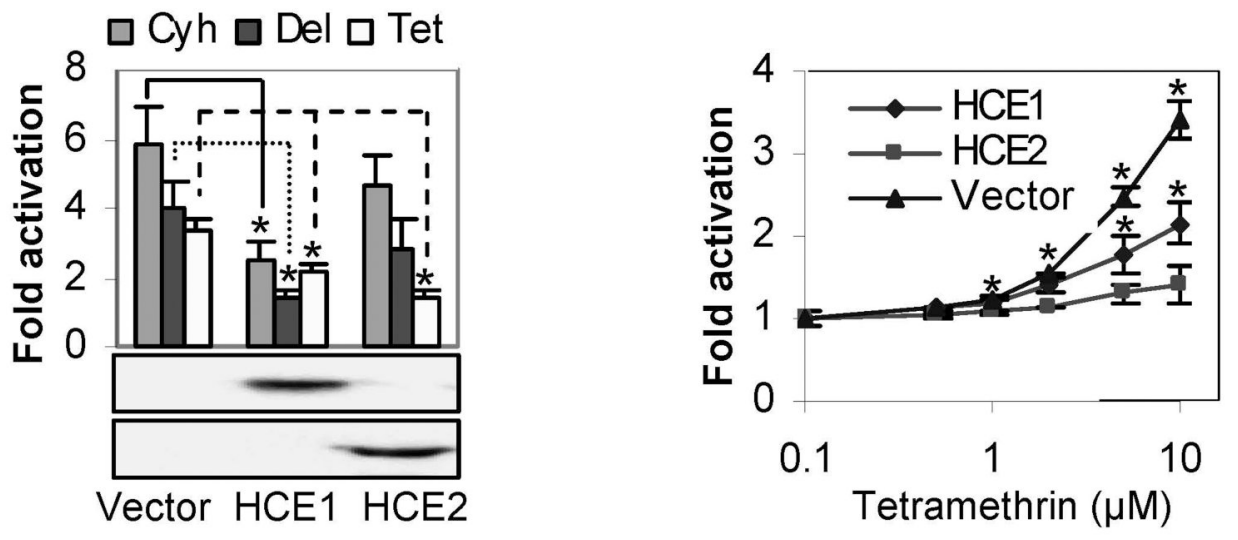

Fig. 5. Activation of human PXR and effect of carboxylesterase on the activation

(A) Activation of the chromatinized CYP3A4-ER6 reporter by pyrethroids A stable transfected line (hPXR-HRE) constitutively expressing human PXR and harboring a PXR element reporter was seeded in 96-well plates in DMEM supplemented with 10\% delipided FBS. After 12-h, cells $(\sim 80 \%$ confluence) were treated for $24 \mathrm{~h}$ with a pyrethroid $(10 \mu \mathrm{M})$ or the same volume of DMSO. Cells were harvested in passive lysis buffer and lysates $(10 \mu \mathrm{l})$ were assayed for firefly luciferase activity. The luminescence signal was normalized based on the amount of protein, and the ratio of a pyrethroid over DMSO treatment served as fold induction. (B) Effect of carboxylesterase on PXR activation The hPXR-HRE cells were transfected again with HCE1, HCE2 or the corresponding vector. The transfected cells were then harvested and re- 
plated in 48 -well plates at $8 \times 10^{4} /$ well. After an overnight incubation, cells were treated with lambda-cyhalothrin $(10 \mu \mathrm{M})$, deltamethrin $(10 \mu \mathrm{M})$ or tetramethrin $(0.5,1,2,5$ and $10 \mu \mathrm{M})$ or the same volume of DMSO. Lysates were prepared and analyzed for luciferase activity as described above. To accommodate logarithmic conversions of the data on the concentrationdependent activation by tetramethrin, the DMSO control is labeled as $0.1 \mu \mathrm{M}$. Western blotting was performed with lysates $(1 \mu \mathrm{g})$ from carboxylesterase or vector transfected cells.

$*$ Statistically significant from vehicle control $(\mathrm{p}<0.05)$. The data in this figure were assembled from three separate experiments. 


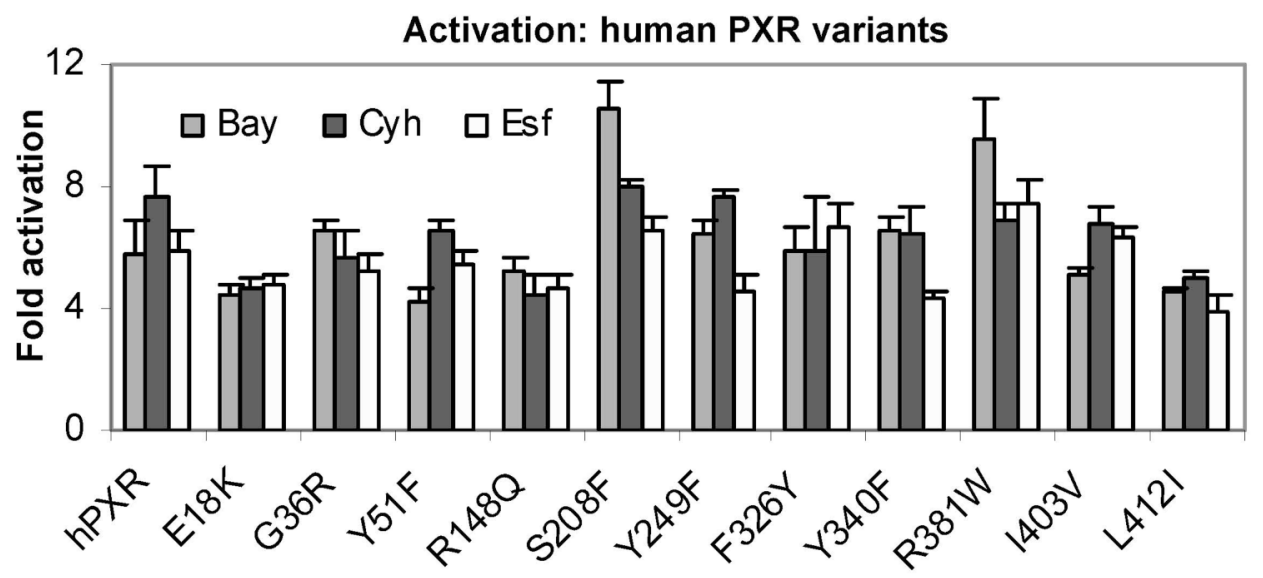

B

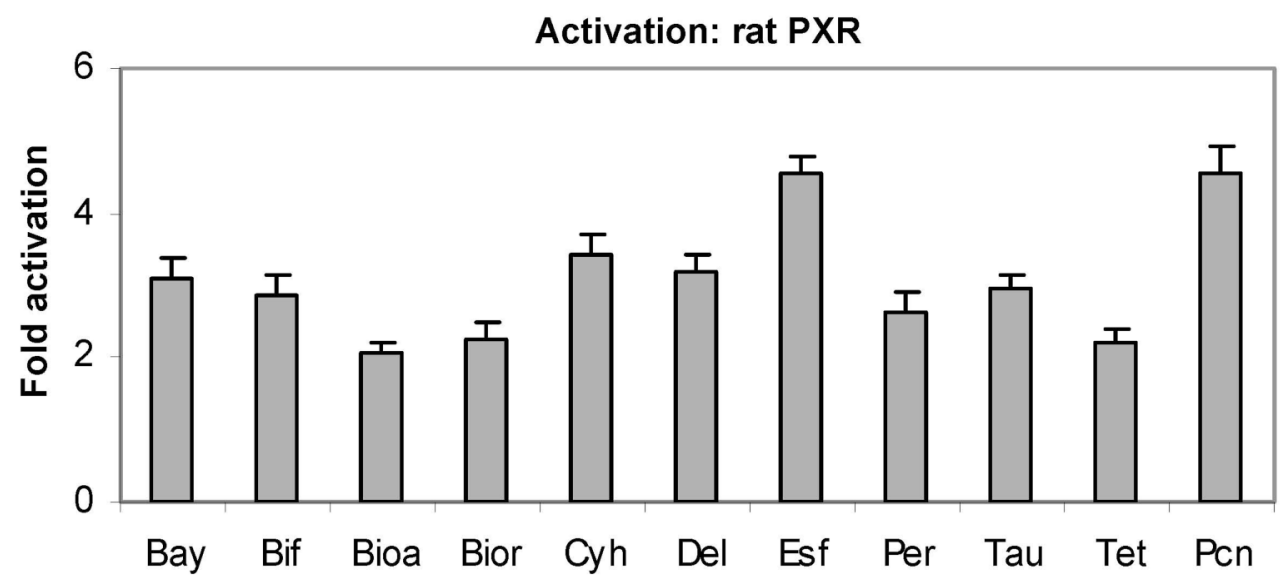

Fig. 6. Activation of human PXR variants or rat PXR

(A) Activation of human PXR variants by pyrethroids HepG2 cells were plated in 48-well plates in DMEM supplemented with $10 \%$ fetal bovine serum at a density of $6 \times 10^{4}$ cells per well. Transfection was conducted by FuGene HD after the cells reached $80 \%$ confluence. The transfection mixtures contained $100 \mathrm{ng}$ of a PXR construct, $50 \mathrm{ng}$ of reporter plasmid CYP3A4DP-Luc, and $5 \mathrm{ng}$ of TK-Renilla luciferase plasmid. The transfected cells were treated with a pyrethroid at $10 \mu \mathrm{M}$ for $24 \mathrm{~h}$. Luciferase activities were determined with a dual luciferase kit. (B) Activation of rat PXR by pyrethroids The experimental procedure was the same as described above but a human PXR construct was replaced with rat PXR construct (Zhang et al., 1999). The data in this figure were assembled from three separate experiments. 
Table I

Purity and retention time of pyrethroids

\begin{tabular}{lllll}
\hline Pyrethroid & Purity & Type & RT (min) & LD $_{\mathbf{5 0}}(\mathbf{m g} / \mathbf{k g})^{\boldsymbol{b}}$ \\
\hline Baythroid (Bay) & $98 \% d$ & II & $9.97^{c}$ & 900 \\
Bifenthrin (Bif) & $97.2 \%$ cis-2.5\% trans & I & 11.03 & 545 \\
Bioallethrin (Bioa) & $3 \%$ cis-96\% trans & I & 9.93 & 425 \\
Bioresmethrin (Bior) & $3 \%$ cis-96\% trans & I & 9.98 & 1244 \\
Deltamethrin (Del) & $99 \%$ & II & 10.01 & 535 \\
Esfenvalerate (Esf) & $99.5 \% d$ & II & 10.09 & 325 \\
lambda-Cyhalothrin (Cyh) & $99 \% d$ & II & 9.97 & 56 \\
Permethrin (Per) & $46 \%$ cis-52\% trans & I & $10.18,10.41$ & 383 \\
tau-Fluvalinate (Tau) & $95 \%{ }^{d}$ & II & 10.41 & 26 \\
Tetramethrin (Tet) & $99{ }^{d}$ & I & $8.72^{c}$ & 4640 \\
\hline
\end{tabular}

\footnotetext{
${ }^{a}$ Retention time

$b_{\text {the median lethal dose (oral in rats or mice) }}$

$c$ with overlapping peaks

$d_{\text {mix of chiral isomers with one isomer being } 90 \% \text { or higher. }}$
} 
Table II

Gene, Taqman probe and accession number

\begin{tabular}{lll}
\hline Gene & Assay identification & Accession number \\
\hline Carboxylesterase-1 (HCE-1) & Hs00275607_m1 & NM_001266 \\
Carboxylesterases-2 (HCE-2) & Hs00187279_m1 & NM_198061 \\
Cytochrome P450 3A4 (CYP3A4) & Hs00604506_m1 & NM_017460 \\
Glyceradehyde-3-phosphate dehydrogenase (GAPDH) & 4352934E & NM_002046 \\
Polymerase (RNA) II polypeptide A (PoII) & Hs01108291_m1 & NM_000937 \\
Pregnane X receptor (PXR) & Hs00243666_m1 & NM_033013 \\
\hline
\end{tabular}

